\title{
DIÁLOGOS DA PESQUISA COM OS ESTUDOS EM ANTROPOLOGIA VISUAL E DA IMAGEM
}

\author{
Artur do Canto Wilkoszynski ${ }^{1}$
}

\section{Considerações iniciais}

Este trabalho tem por objetivo relacionar aspectos da pesquisa no âmbito da pósgraduação em Planejamento Urbano e Regional com o processo de aprendizado em "Antropologia Visual e da Imagem", disciplina cursada junto ao PPGAS/IFCH/UFRGS no segundo semestre do ano próximo passado. Inicialmente pensado sob a forma de um relato que refletisse a experiência junto à disciplina, por sugestão dos pareceristas da Revista Iluminuras, o presente trabalho é apresentado aqui sob a forma de um relato desta vivência.

A relação entre os temas tratados pela disciplina e os referenciais teóricometodológicos do Imaginário Social e do Projeto por Cenários adotados na pesquisa está posta na centralidade das imagens nestes campos do conhecimento. Neste sentido, o campo da imagem é explorado como forma de pensar e projetar o território urbano (aqui trazido como área de formação, atuação e interesse do pesquisador), em especial por sua capacidade narrativa e de interpretação do imaginário social. A escolha metodológica deriva entre os aspectos da leitura e decifração do imaginário social (a partir da visão de Walter Benjamin), das estratégias projetuais evidenciadas no pensamento por cenários e, ainda, pela análise e interpretação de imagens no âmbito da antropologia visual; em todos os casos com foco nas analogias e/ou complementaridades da capacidade hermenêutica das imagens em cada um dos campos de conhecimento.

Retomando os objetivos principais da pesquisa, em primeiro lugar busca-se o deslocamento do imaginário social desde o campo das narrativas e das representações sobre o social urbano para vê-lo também como uma ferramenta na elaboração de projetos urbanos. Em segundo lugar, no pensamento por cenários, busca-se aplicar a montagem de imagens dialéticas que, elaboradas a partir da combinação de imagens e textos, explicitam alternativas para o projeto urbano. O uso combinado de "imagens dialéticas" e de "gráficos de polaridades", instrumentos analíticos respectivos a cada um dos referenciais

\footnotetext{
${ }^{1}$ Universidade Federal do Rio Grande do Sul, Brasil.
} 
mencionados, permite qualificar a leitura e construção de narrativas por imagens e, assim, operar o cruzamento e articulação de metodologias. Esses movimentos pretendem demonstrar a pertinência da adoção do imaginário social como ferramenta tanto para a leitura/diagnóstico das realidades urbanas como para a proposição de alternativas de projeto através do Projeto por Cenários. Assim, combinando as possibilidades que o imaginário social oferece para a decifração de valores, aspirações e necessidades no âmbito do urbanismo ao caráter analítico-propositivo dos cenários, vislumbra-se a complementaridade entre estes instrumentos.

Em termos operacionais, cabe lembrar que, segundo Pesavento (2002a: 24), o imaginário social faz a leitura do urbano a partir de um sistema de representações coletivas de ideias e imagens que é construído pelos homens para atribuir significado ao social. Assim, tendo em vista a decifração do imaginário, o método escolhido é a combinação da montagem de "imagens dialéticas", na perspectiva de Walter Benjamin, com a produção de "gráficos de polaridades", no pensamento por cenários. As imagens, visuais ou mentais, quando articuladas através de montagens, são a chave para a construção das narrativas que dão a ver o imaginário social e, como efeito desta interpretação, permitem a imaginação de cenários necessários, possíveis ou desejados para o espaço das cidades.

A gênese da pesquisa, bem como a deste trabalho, se dá a partir desses movimentos dialógicos no deslocamento e a articulação entre os referenciais teórico-metodológicos nomeados e o estudo das imagens. Justificam-se seus propósitos pela busca em demonstrar a possível complementaridade na produção e interpretação de imagens, as quais contribuem para a decifração do imaginário e, consequentemente, para a produção de sentido nos e dos projetos. Para conseguir esta complementaridade, é importante haver uma conjugação de alguns conceitos fundantes, presentes nos referenciais teórico-metodológicos adotados, porém com aplicações distintas em seus âmbitos específicos. Os conceitos de imagem, montagem e narração são centrais nestes campos do conhecimento e, por isso mesmo, são tanto a origem da articulação pretendida como o próprio amálgama entre eles.

No âmbito do mestrado, a pesquisa centrou-se na investigação da arquitetura como elemento constituinte do imaginário social. Com este objetivo, adotaram-se como representações a arquitetura contemporânea em Porto Alegre, especificamente aquela produzida no âmbito acadêmico em contraposição com as realizações do mercado 
imobiliário. A partir do método de montagem benjaminiano, nomeadamente por meio da construção de imagens dialéticas, estas diferentes produções foram colocadas em choque a fim de permitir a interpretação do imaginário relativo a cada segmento.

Já no âmbito do doutorado, e a partir dos conhecimentos adquiridos como aluno da disciplina de Projeto por Cenários, cursada junto ao PROPUR/UFRGS, a pesquisa buscou retomar as investigações sobre o imaginário social, propondo agora um cruzamento daqueles conhecimentos com o pensamento por cenários. Esta articulação proposta tem em vista a articulação do caráter interpretativo do imaginário com as técnicas de análise e proposição do projeto por cenários, em especial buscando a aplicabilidade prática daqueles conhecimentos às práticas de planejamento urbano.

Ainda no âmbito do doutorado, o contato com a disciplina "Antropologia visual e da Imagem" colocou em perspectiva na pesquisa novos conteúdos e conhecimentos, ampliando o arsenal de instrumentos e técnicas para a produção e interpretação de imagens. Através das diversas operações imagéticas ali experimentadas, além da clara ampliação de horizontes epistêmicos, foi possível vislumbrar alguns novos desafios e possibilidades para a pesquisa. Através de relatos sobre o processo de aprendizado, entrecruzado com conhecimentos adquiridos, esta experiência é reproduzida de forma mais detalhada na seção que segue.

\section{Diálogos da pesquisa com os estudos da Antropologia visual e da imagem}

Em sequência às considerações iniciais, este trabalho estrutura-se na forma de um diálogo do pesquisador com os temas e as proposições da disciplina para cada um dos encontros. Tendo em vista a arquitetura e urbanismo como a área de formação, atuação e interesse da pesquisa, com especial foco no campo das imagens, mesmo que a grande parte das questões abordadas pelo tema e programa da disciplina tenham se mostrado de grande importância, cabe reconhecer que nem todas elas tiveram igual peso e pertinência. Assim sendo, o diálogo a seguir irá destacar as temáticas de encontros que despertaram maior interesse ou curiosidade por estarem mais clara e diretamente articuladas aos objetivos da 
pesquisa. As demais, mesmo reconhecidamente importantes para o campo dos estudos em antropologia visual, não serão comentadas aqui de forma particularizada.

Ao adotar-se um mecanismo dialético entre o aluno e a disciplina, busca-se fazer uma reflexão sobre as contribuições de cada um dos temas abordados com as investigações pretendidas pela pesquisa da tese, em especial através dos exercícios propostos. Conforme a dinâmica proposta, a cada aula um exercício prático foi encomendado aos alunos estabelecendo, através deles, a articulação com a literatura e teorias a serem discutidas no encontro seguinte bem como uma vivência direta das questões a abordar. Assim, ao colocar-se um tipo de lente de aumento sobre as experiências teóricas e/ou práticas vividas, pretende-se que este olhar mais particularizado contribua na avaliação da validade do processo de aprendizado. Essa analise pretende ainda demonstrar o efetivo cruzamento dos distintos saberes relativos ao caráter hermenêutico das imagens com os propósitos da pesquisa.

O primeiro encontro da disciplina teve como proposta abordar as "sensibilizações, situações concretas e a pesquisa etnográfica com imagens". Em dinâmica de diálogo entre as professoras e a turma, foram discutidos o programa, o método adotado, os interesses individuais pela disciplina, a partir de suas áreas de origem, seu prévio envolvimento e sua relação com recursos audiovisuais em sua trajetória acadêmica ou fora dela. Destacadamente, o diálogo avançou pelo campo de problemas da disciplina e seus desdobramentos, evidenciando que diversos dos temas a tratar seriam de interesse para a pesquisa.

Para o segundo encontro a temática proposta foi a "linguagem das formas e a propriedade do mundo das coisas" articulada com a apresentação de "um objeto afetivo ou não (?) de sua escolha”. Este primeiro exercício buscou, a partir da sensibilização pelas formas, traduzir a motivação da escolha do objeto seja quanto a sua estética, imagem, subjetividade, etc. A partir das leituras sugeridas, a partir do olhar de Henri Focillon (1988), analisa as formas de espaço, na matéria, no espírito e no tempo, revelando o que de ilusório existe na distinção entre forma e conteúdo e mostrando-nos que a arte é mais que uma simples sucessão de estilos e momentos". Segundo o autor, acerca da natureza ativa da forma "pode considerar-se que a matéria impõe a sua própria forma, à forma. [...] as matérias trazem em si um certo destino ou, se quiserem, uma certa vocação formal. [...] São 
formas e por isso mesmo atraem, limitam ou desenvolvem a vida das formas da arte" (Focillon, 1988: 65). Transferindo este olhar sobre a forma ao campo da antropologia, Rocha (1995) afirma que "a imaginação criativa orienta e modela a percepção dos dados sensíveis que configuram o mundo social”.

O terceiro encontro propôs abordar o "percurso no tempo e suas formas". Ao formularem-se estruturas narrativas imagéticas (mitos, poesias, álbuns fotográficos, letras de música, roteiros de filmes, trechos musicais) revela-se o nosso mundo "sensível e da anterioridade ontológica do simbolismo sobre a significância audiovisual" por meio das motivações das escolhas feitas. As imagens apresentadas, portanto, revelaram um pouco de nossas pertenças e como representamos a nós mesmos através daquelas estruturas narrativas. Para David MacDougall (1998), esta alteridade vivenciada através da arte e da ciência ajuda a compreender a existência dos outros no mundo mas isso ainda depende da maneira como lidamos com a prática diária do ver (o outro). Nesse sentido, o autor faz um alerta:

"O significado que achamos no que vemos é tanto uma necessidade como um obstáculo. Significados orientam nossa visão. Significados nos permitem categorizar objetos. Os significados impregnam a imagem de uma pessoa com tudo o que sabemos sobre ela. É o que os torna familiarizado; trazendo-os para a vida cada vez que vê-los. Mas o significado, quando imposto sobre as coisas, pode também cegar-nos, fazendo-nos ver apenas o que esperamos ver ou distrair-nos de ver grande coisa". (MacDougall, 1998: 1)

Pierre Jordan (1995), referindo-se aos primórdios do cinema como instrumento de registro etnográfico, assinalou a tentativa, e também a dificuldade, de perceber o outro sem esbarrar num etnocentrismo. Para ele, foi através do registro de imagens (documentais ou não) e de um olhar prolongado e cotidiano pelo não-nativo que passou a ser possível compreender a complexidade cultural de outros grupos ou povos. O filme "Nanook of the North" (Robert Flaherty, 1922), marcou uma ruptura no caráter documental destes registros ao instaurar uma espécie de "etnoficção" ao narrar através da construção de um discurso ficcional através das imagens fílmicas. Através das reflexões de aula e das leituras, foi possível formular uma analogia entre o papel do antropólogo e o do urbanista. Trasladada ao campo do projeto urbano, é igualmente desafiadora ao urbanista a missão de isentar-se de visões ontológicas ao propor um 'espaço-discurso' de vida para o outro. Narrar e 
inventar através da materialidade do espaço requer, igualmente, a experiência. A observação do(s) usuário(s) de um espaço urbano poderá esclarecer dinâmicas e valores próprios daquele grupo, evitando-se um tipo de "etnocentrismo projetual".

O quarto encontro abordou primeiramente o "campo conceitual da Antropologia Visual e da Imagem" e, num segundo momento, “imagem, imaginário, imaginação", conceitos centrais para o campo de estudo das imagens e articuladores dos conhecimentos da disciplina de antropologia visual bem como do urbanismo, conforme a visão teóricometodológica adotada na pesquisa. A tarefa de apresentar uma imagem (figurativa) buscou refletir sobre a escolha da imagem a partir do enunciado "dentro-do quadro, fora do quadro e para além do quadro. Que história você conta para fazer a imagem vibrar?" À luz de Bachelard, o exercício buscou trazer à consciência um processo de imaginação criativa e dinâmica e, portanto, não passiva diante da materialidade dos objetos. Em "O ar e os sonhos. Ensaio sobre a imaginação do movimento", Gaston Bachelard reflete acerca da ação imaginativa na qual o homem assume uma atitude interveniente sobre a matéria. Ao romper com a tradição formalista do pensamento, na qual o sentido do olhar e a contemplação passiva da realidade são privilegiados, Bachelard conduz para uma imaginação ativa e transformadora. A imaginação dinâmica privilegia a vontade de criar, manipular, transformar a matéria; seu caráter frente à materialidade é produtivo.

Num salto para o oitavo encontro, a proposta de estudos investigou "os papéis (as ações) e os cenários (os lugares)". Através do uso da técnica de desenho, o exercício propôs a construção de um breve relato a partir das experiências de percursos em que vivem e agem os interlocutores/ personagens, ou ainda uma situação de interação especifica. O registro gráfico, inspirado nos conceitos de Michel De Certeau (1990), demandou aos alunos uma observação das práticas e relações sociais ao invés de ter o indivíduo como foco da análise. Para o autor, a relação social é determinante do indivíduo e, por isso, só se pode apreendê-lo em função de suas ações atreladas a seus lugares de vivência, ou seja, por meio de suas práticas sociais. De Certeau afirma que, diante da complexidade do âmbito urbano das ações sociais, a alternativa para o desenvolvimento de uma outra apreensão da cidade e suas práticas demanda um outro olhar menos generalizante e que busca: 


\begin{abstract}
"Analisar as práticas microbianas, singulares e plurais, que um sistema urbanístico deveria administrar ou suprimir e que sobrevivem a seu perecimento; seguir o pulular desses procedimentos que, muito longe de ser controlados ou eliminados pela administração panóptica, se reforçaram em uma proliferação ilegitimada, desenvolvidos e insinuados nas redes de vigilância, combinados segundo táticas ilegíveis mas estáveis a tal ponto que constituem regulações cotidianas e criatividades sub-reptícias que se ocultam somente graças aos dispositivos e aos discursos, hoje atravancados, da organização observadora. (De Certeau, 1990: 175).
\end{abstract}

Os encontros de número nove e dez trouxeram, respectivamente, os desafios de "esculpir esteticamente o tempo e o espaço" e investigar "as situações (as intrigas)". Como exercício foi solicitada uma entrevista (preferencialmente com vídeo ou gravador) e escolher um trecho desta para apresentar a relação do personagem com o contexto urbano, sua casa, rua, bairro, cidade, rede de pertença, evocando as práticas cotidianas, os saberes e os fazeres. Segundo Rocha (2010) “o mote da pesquisa antropológica, sobretudo através do seu método etnográfico, consiste em observar e entrevistar estes citadinos em seus cotidianos". A autora afirma ainda que, desta forma, é possível entender que o conhecimento da realidade urbana, enquanto fenômeno social, demanda a pesquisa da memória dos indivíduos e grupos tendo como base suas narrativas e trajetórias numa multiplicidade de situações de convívio formal ou informal, pública ou privada. No âmbito da pesquisa, assumida uma filiação às questões imagéticas, esta aproximação pode ser igualmente aplicável, como teoria ou prática, aos desafios de análise/diagnóstico que antecedem a elaboração do projeto urbano. Compreendidas as intrigas, parte-se para a 'escultura estética' do tempo e do espaço da urbe.

Nos encontros onze e doze, abordamos "as técnicas (a imaginação material) fotografia - fazer reverberar o tempo". Tendo em vista o tempo necessário para pesquisas de campo e execução, o exercício apresentado nesta última aula combinou-se a outro solicitado por ocasião do nono encontro. Os temas destes exercícios foram, primeiramente, a apresentação de um roteiro de uma história problematizando o tema de pesquisa, com base no 'sistema BIEV', Num segundo momento, na apresentação do resultado de uma narrativa etnofotográfica com dez fotografias elaborada a partir do roteiro. Novamente à luz

${ }^{2} \mathrm{O}$ 'sistema BIEV' refere-se ao modelo adotado pelo BIEV - O Banco de Imagens e Efeitos Visuais é um Projeto do Laboratório de Antropologia Social, pertencente ao Núcleo de Estudos sobre Culturas Contemporâneas/NUPECs, do Programa de Pós-Graduação da Universidade Federal do Rio Grande do Sul, e está sediado no Instituto Latinoamericano de Estudos Avançados/ILEA. 
de Bachelard, o exercício buscou exercitar a imaginação criativa, dinâmica e, portanto, interveniente e transformadora sobre a matéria em foco. No livro, "O olho interminável", Jacques Aumont acentua a diferença entre a imagem pictórica e o instante registrado pela fotografia como configuração que efetivamente ocorreu. Neste sentido, Aumont afirma:

"O cinema é herdeiro da fotografia parada e de seu inquestionável vínculo com a realidade visível. O cineasta não é impedido de coisa alguma, contando que suas intenções sejam puras" (Aumont, 2004).

No capítulo "Da cena a tela, ou o espaço da representação", Aumont aprofunda questões da linguagem cinematográfica ao relativizar as articulações entre o "campo e o fora-de-campo" como elementos que compõe o imaginário e a ficção ou ainda entre o "quadro e fora-de-quadro" como elementos para a construção da dimensão ficcional de uma narrativa. Segundo o autor, o "fora-de-campo" é um lugar potencialmente virtual, uma continuação do limite do campo delimita, enquanto a noção do quadro está no limite de um campo onde se centra a representação cinematográfica delimitando o espaço e tempo do imaginário, o espaço da representação. Para Boris Kossoy (2002), o documento fotográfico é sempre uma representação feita a partir do real mas intermediada pelo fotógrafo. Esta produção da imagem fotográfica é feita a partir de sua forma particular de compreensão do real, constituindo, portanto, uma realidade imaginada ou ficcional. Para a pesquisa em curso, o tema da fotografia mostrou-se de grande relevância por estar diretamente vinculado à produção, registro e representação das imagens visuais. A fim de explicitar a dialética das imagens do projeto urbano, assume-se que construção de cenários será baseada no uso de fotografias, tanto pela facilidade de produção como de reprodução. Quanto ao exercício da narrativa etnofotográfica, apesar da complexidade inicial para a realização dos registros (tematização, técnicas de registro, manuseio do equipamento) foi possível contabilizar um importante aprendizado quanto à criação narrativa de imagens fotográficas.

Para o encontro de número treze, foi solicitado que estudássemos "os dramas (as narrativas)". O exercício consistiu em pesquisa em acervo de imagens convergindo semanticamente com as imagens produzidas para a pesquisa (coleções fotográficas, acervos 
cinematográficos, sonoros ou audiovisuais, acervos de outras etnografias, etc). Assim, acerca do chamado "patrimônio etnológico" de um grupo e tendo em vista a produção e geração de coleções etnográficas, segundo Rocha e Eckert (2013), "quanto mais constelações de imagens apresentarem desde um mesmo ponto de convergência, tanto mais direções para o antropólogo construir conhecimento sobre uma determinada ordem de fenômeno". Novamente, identificou-se aí uma analogia possível com a tarefa do urbanista diante da identificação/interpretação das coleções de imagens que narram o imaginário coletivo de um grupo para o qual se pretende projetar. Apesar de serem distintos os propósitos específicos do antropólogo/etnógrafo daqueles do arquiteto/urbanista, percebe-se a pertinência do "método de convergência" quanto ao propósito geral da interpretação das imagens coletivas.

Para o décimo quinto encontro e encerramento da disciplina, "os ritmos" foi o tema proposto. Tendo em vista o tempo necessário para pesquisas de campo e execução, o exercício apresentado nesta última aula combinou-se a outro solicitado por ocasião do nono encontro. O tema destes exercícios consistiu na apresentação de um roteiro de filmagem (áudio-vídeo) elaborado para saída de campo com base no 'sistema BIEV' e, num segundo momento na apresentação do resultado em vídeo a partir do roteiro. Acerca deste último exercício, com base na visão de Duarte (Duarte et al, 2010) no artigo "Olhares possíveis para o Pesquisador em Arquitetura" foi possível concluir que, entre as importantes contribuições do vídeo etnográfico, destaca-se sua capacidade articuladora das narrativas do ambiente, em especial através da perspectiva dinâmica observada nos usos e usuários, conferindo ao espaço a vitalidade geralmente ausente nas fotografias do espaço construído. Para os autores:

\footnotetext{
“O vídeo etnográfico, seja como instrumento de observação, transcrição e interpretação de realidades sociais ou instrumento de ilustração e difusão das pesquisas, o conjunto imagem-som-movimento, recolhido em tempo sincronizado, é um excelente meio para a captação e exame da experiência humana na ambiência”. (Duarte et al, 2010).
}

Por fim, concluídas as articulações propostas pelo diálogo entre os aprendizados proporcionados pela disciplina e os objetivos da pesquisa em curso, nesta última seção serão apresentadas as considerações finais e conclusões gerais obtidas. 


\section{Considerações finais}

Conforme considerado inicialmente, a validade de uma revisão epistemológica no urbanismo evidencia-se pela dificuldade de interpretar e intervir na diversidade e complexidade urbana contemporânea, em especial quando consideradas as práticas de planejamento vigentes. Estes fatores associados indicam a urgência de uma reflexão teórico-metodológica feita à luz de distintos referenciais e, consequentemente, da adoção de novas ferramentas para a interpretação das questões relacionadas à imagética e ao imaginário contemporâneo. Haja vista a realidade e complexidade urbana que já não podem prescindir de um caráter mais plural e abrangente em seu planejamento, ao adotar-se o referencial teórico-metodológico do imaginário social, seja como leitura das heterogeneidades, seja como resposta projetual a elas, vislumbra-se uma alternativa. Assim sendo, em cruzamento com o estudo do imaginário social, a metodologia de projeto por cenários oferece uma nova abordagem para o projeto urbano através da qual busca-se preencher lacunas deixadas pelos métodos de planejamento tradicional. No sentido desta complementaridade, o caráter operativo das Imagens Dialéticas em Benjamin e a construção de polaridades no Projeto por Cenários à luz de Bachelard sugere um cruzamento entre ambas. Somando-se a estas proposições, a experiência adquirida em Antropologia Visual mostrou ser pertinente e desejável uma filiação aos seus métodos específicos. Sendo o "anthropos" um elemento indissociável do urbano, a articulação de saberes e experiências entre ambos os campos do conhecimento poderá resultar em um olhar mais aberto e flexível sobre o coletivo, tal como se vêm buscando na pesquisa. 


\section{Referências}

AUMONT, Jacques. O olho interminável. São Paulo: Cosac \& Naify, 2004, p. 139-166.

BACHELARD, Gaston. A poética do espaço. São Paulo: Martins Fontes, 2000. . A intuição do instante. Campinas: Verus Editora, 2007.

$O$ ar e os sonhos. Ensaio sobre a imaginação do movimento. São Paulo:

Martins Fontes, 2001.

BOLLE, Willi. Fisiognomia da metrópole moderna. Representação da história em Walter Benjamim. São Paulo: EDUSP, 1994.

BENJAMIN, W. Passagens. Belo Horizonte: Editora da UFMG; São Paulo: Imprensa Oficial, 2006.

Pequena História da Fotografia. In: Walter Benjamin. Coleção Grandes Cientistas Sociais. São Paulo: Atica, 1991.

DE CERTEAU, M. "Práticas de espaço". In: A invenção do cotidiano, as artes de fazer. Petrópolis : Vozes, 1990, p. 169-192.

DELEUZE, G.; GUATTARI, F. Mil Platôs; capitalismo e esquizofrenia. Volume 4. São Paulo: Editora 34, 1997.

DUARTE, C. R. S.; PINHEIRO, E.; BRASILEIRO, A.; UGLINE, P. Olhares possíveis para o Pesquisador em Arquitetura. Revista Interfaces (UFRJ), v. 16, p. 130-145, 2010.

DURAND, G. As estruturas antropologicas do imaginario: introdução a arqueologia geral. São Paulo: Martins Fontes, 1997.

ECKERT, C. e ROCHA, Ana Luiza C. Antropologia da e na cidade. Porto Alegre: Marca Visual, 2013. Capítulo Cidade sitiada, o medo como intriga, p. 143-187.

Etnografia da duração. Porto Alegre: Marca visual, 2013, p. 105-127.

FOCILLON, Henri. O mundo das formas. In: A vida das formas, Lisboa: Edições 70, 1988. JORDAN, Pierre. Primeiros contatos, primeiros olhares. In Cadernos de Antropologia e Imagem 1. Antropologia e Cinema Primeiros Encontros. Rio de Janeiro: UERJ, 1995.

KOSSOY, B. A Imagem fotográfica: sua trama, suas realidades. In: Realidades e ficções na trama fotográfica. São Paulo: Atelier Editorial, 2002.

MacDOUGALL, D. Meaning and Being. In: The corporeal image. Film, ethnography and the senses. Princeton University Press, Princeton and Oxford, 1998, p. 1-9.

MANZINI, E.; JÉGOU, F. Design degli scenari. In: MANZINI, E.; BERTOLA, P. Design multiverso. Milano: Edizioni Poli.design, 2004.

MOUTINHO, Marcelo. Cenários e visão de futuro. In: Andrade, A. Pensamento Sistêmico: caderno de campo - o desafio da mudança sustentada nas organizações e na sociedade. Porto Alegre: Bookman, 2006.

PESAVENTO, Sandra J. Em busca de uma outra história: imaginando o imaginário. In: Revista Brasileira de História. São Paulo: Editora Contexto, 1995.

Memória, História e Cidade: lugares no tempo, momentos no espaço.

ArtCultura, Revista do Nehac, Universidade Federal de Uberlândia, v. 4, n. 4, p. 23-35, 2002.

. Muito além do espaço: por uma história cultural do urbano. In: Revista

Estudos Históricos. Rio de Janeiro: Editora da Fundação Getúlio Vargas FGV / CPDOC, vol.8, n.16, p. 279-290, 1995. 
. O imaginário da cidade: visões literárias do urbano. Paris, Rio de Janeiro e Porto Alegre. $2^{\text {a }}$ Ed. Porto Alegre: Editora da Universidade / UFRGS, 2002.

REYES, Paulo Edison Belo. Construção de Cenários no design: o papel da imagem e do tempo. In: Anais do $9^{\circ}$ Congresso Brasileiro de Pesquisa e Desenvolvimento em Design. São Paulo: Anhembi Morumbi, 2010.

Construção de cenários - uma proposta metodológica. In: 54 International Federation for Housing and Planning - World Congress Porto Alegre 2010 - Building communities for the cities of the future, 2010, Porto Alegre. - 54 IFHP World Congress Porto Alegre 2010. - Porto Alegre: EDIPUCRS, 2010. v.3 Ppa35. p. 01-10.

. Tudo o que não invento é falso: por uma epistemologia da imaginação criadora no design. Strategic Design Research Journal, v. 3, p. 01-12, 2010.

ROCHA, A.L.C. Antropologia das formas sensíveis; entre o visível e o invisível, a floração de símbolos. In: Horizontes Antropológicos. Antropologia Visual, Ano 1, vol 2, 1995.

Cidade narrada, tempo vivido: estudos de etnografias da duração. RUA [online]. 2010, no. 16. Vol.1.

ROCHA, A.; ECKERT, C. Etnografia da Duração: antropologia das memórias coletivas em coleções etnográficas. Porto Alegre: Marcavisual, 2013.

SECCHI, Bernardo. Primeira lição de urbanismo. São Paulo: Editora Perspectiva, 2006.

VAN DER HEIJDEN, K. Planejamento por cenários: a arte da conversação estratégica. Porto Alegre: Bookman, 2009.

Recebido em: 14/03/2015

Aprovado em: 10/06/2015 